\title{
LEVANTAMENTO FITOSSOCIOLÓGICO DE PLANTAS INFESTANTES NA ÁREA EXPERIMENTAL DA UNIVERSIDADE FEDERAL DO TOCANTINS SUBMETIDA A DIFERENTES CULTIVOS
}

Paulo Henrique Aquino Marinho'; Rhonan Martins de Sousa'; Paulo César Alves de Oliveira Medeiros ${ }^{1}$; Tayanne Graciette Nascimento Silva ${ }^{1}$; Marcos Giongo ${ }^{2}$

'Mestrando do Programa de Pós-Graduação em Ciências Florestais e Ambientais, Campus Universitário de Gurupi / Universidade Federal do Tocantins, Gurupi, TO (depaulohenrique@gmail.com)

2Professor Doutor do Programa de Pós-graduação em Ciências Florestais e Ambientais, Campus Universitário de Gurupi / Universidade Federal do Tocantins, Gurupi, TO

Recebido em: 15/04/2017 - Aprovado em: 22/07/2017 - Publicado em: 31/07/2017 DOI: 10.18677/Agrarian_Academy_2017a31

\begin{abstract}
RESUMO
A análise da cobertura vegetal por meio de levantamento fitossociológico é de extrema importância no processo de manejo e controle de plantas infestantes. Nesse sentido, foi realizado um levantamento fitossociologico na área experimental da Universidade Federal do Tocantins (UFT), campus de Gurupi-TO. O levantamento foi realizado utilizando a metodologia do quadrado inventário, onde foram lançadas aleatoriamente 10 parcelas de um gabarito com dimensões de $1 \mathrm{~m}^{2}$ em quatro diferentes cultivos: eucalipto, pinhão-manso, bananal e pastagem degradada. Nas áreas de estudo foram identificadas 23 espécies distribuídas em 12 famílias, e a família Poaceae foi a de maior destaque, seguida por Fabaceae e Amaranthaceae. Nos plantios de eucalipto, pastagem degradada, bananal e pinhão manso, as espécies de maior importância foram a Diodia teres, Panicum maximum, Mimosa pudica e Digitaria horizontales, respectivamente. Analisando todas as áreas, as espécies que obtiveram maior frequência foram: Diodia teres, Commeliana benghalensis e Sida rhombifolia, todas com 0,9 de frequência. Em relação a densidade as espécies mais presentes no campus foram: Diodia teres $(25,2$ plantas. $\left.\mathrm{m}^{-2}\right)$, Panicum maximum (10,2 plantas. $\mathrm{m}^{-2}$ ) e Brachiaria decumbens $(14,5$ plantas $/ \mathrm{m}^{2}$ ). As espécies que tiveram maior ocorrência em agregado foram: Mimosa pudica (28,7\%), Diodia teres (28,4\%) e Cyperus esculentus (13,9\%). A análise fitossociológica permitiu avaliar a dinâmica da vegetação infestante do local de estudo e com isso elaborar estratégias para o manejo e controle.
\end{abstract}

PALAVRAS-CHAVE: Bananal, Eucalipto, Plantas daninhas, Pinhão-manso, Pastagem degradada. 


\title{
PHYTOSOCIOLOGICAL LIFTING OF INFESTANT PLANTS IN THE EXPERIMENTAL AREA OF THE FEDERAL UNIVERSITY OF TOCANTINS SUBMITTED TO DIFFERENT CROPS
}

\begin{abstract}
The analysis of the vegetation cover by means of phytosociological survey is of extreme importance in the process of management and control of weeds. In this sense, a phytosociological survey was carried out in the experimental area of the Federal University of Tocantins (UFT), Gurupi-TO campus. The lifting was carried out using the methodology of the square inventory, where 10 plots of a template with dimensions of $1 \mathrm{~m}^{2}$ were randomly cast in 4 different crops: eucalyptus, banana, jatropha and degraded pasture. In the study areas were identified 23 species distributed in 12 families, where the Poaceae family was the most featured, followed by Fabaceae and Amaranthaceae. In the eucalyptus plantations, degraded pasture, banana and pinhão-manso, the species of greatest importance was Diodia teres, Panicum maximum, Mimosa pudica and Digitaria horizontal, respectively. Analyzing all areas, the species that obtained the highest frequency were: Diodia teres, Commeliana benghalensis and Sida rhombifolia, all with 0,9 of frequency. In relation to density the most present species on campus were: Diodia teres (25,2 plants $\left./ \mathrm{m}^{-2}\right)$, Panicum maximum (10,2 plants $/ \mathrm{m}^{-2}$ ) and Brachiaria decumbens (14.5 plants $/ \mathrm{m}^{-2}$ ) were the most present species on the campus. The species that had the highest occurrence in aggregate were: Mimosa pudica (28,7\%), Diodia teres $(28,4 \%)$ and Cyperus esculentus (13,9\%). The phytosociological analysis allowed to analyze the dynamics of the weed vegetation of the study site and with that to elaborate strategies for its management and control.
\end{abstract}

KEYWORDS: Weeds, Pinhão-manso, Eucalyptus, Bananal, Degraded grassland.

\section{INTRODUÇÃO}

As plantas daninhas são biologicamente um dos principais fatores de restrições para o cultivo de determinada espécie, uma vez que interferem no crescimento da cultura e no desenvolvimento por meio de uma competição por espaço, luz, água e nutrientes, que são essenciais para os processos fisiológicos da planta. Além disso, muitas espécies de plantas daninhas possuem mecanismos de alelopatia, que impedem o crescimento de outras espécies associados a estas (MOURA FILHO et al., 2015).

As plantas daninhas produzem grande quantidade de sementes e propágulos vegetativos, de forma estratégica para a sobrevivência aos estímulos impostos por métodos de controle. Diversos fatores afetam a germinação das plantas daninhas, os quais incluem, umidade e temperatura do solo, intensidade da luz, e aspectos particulares fisiológicos das sementes (MOURA FILHO et al., 2015).

Um problema relevante em áreas de cultivo é o controle de plantas daninhas, devido à capacidade que se destacarem e competir pelos recursos naturais (PACHECO et al., 2016). O grau de interferência de determinada espécie daninha em uma cultura depende de fatores ligados a comunidade infestante como a composição, densidade e distribuição ( et al., 2013). Nesse sentido a caracterização de plantas daninhas, através de métodos de quantificação e identificação, torna-se essencial no processo de manejo e controle, e uma das formas de acessar informações das comunidades vegetais é fazendo um levantamento fitossociológico (MATA et al., 2013). 
Esse método de avaliação, através de levantamento fitossociológico, representa importante ferramenta na tomada de decisões, pois possibilitam comparar a comunidade infestante e avaliar qual o dano que esta causa nas demais. Segundo RODRIGUES et al. (2016), nem todas as espécies possuem a capacidade de interferir no desenvolvimento da cultura, tornando a análise fitossociológica adequada no conhecimento da vegetação.

Pesquisas referentes as técnicas de controles são escassas no cerrado Tocantinense, diante disso, a necessidade de estudos que possibilitam apontar melhores opções para o manejo de plantas daninhas pode contribuir para a tomada de decisão do produtor. O objetivo desse trabalho foi avaliar a comunidade infestante sob diferentes composições de culturas na área experimental da Universidade Federal do Tocantins através do levantamento fitossociológico.

\section{MATERIAL E MÉTODOS}

O levantamento foi realizado no mês de dezembro de 2016, na fazenda experimental da Universidade Federal do Tocantins (UFT) (Figura 1), Campus de Gurupi - TO. O clima do município, segundo Thornthwaite, é do tipo C2wA "a", caracterizado por um clima úmido subúmido, com moderada deficiência hídrica no inverno, a temperatura média anual é de $26^{\circ} \mathrm{C}$, com precipitação média anual entre 1.300 a 1.700 mm, sendo o verão chuvoso e o inverno seco (SEPLAN, 2012).

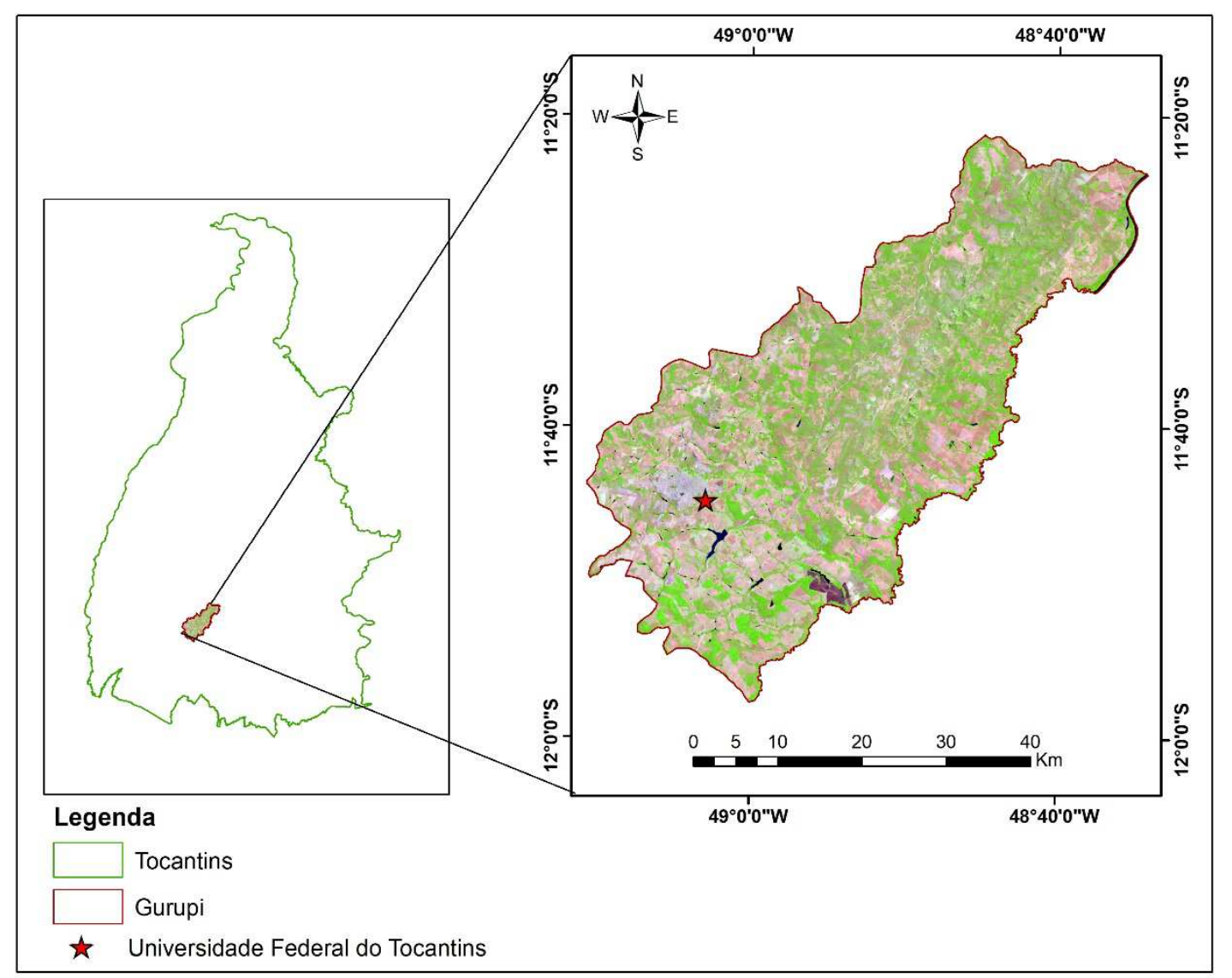

FIGURA 1: Localização da área de estudo

Fonte: Autores

As áreas localizadas na fazenda experimental da UFT são constituídas por pastagem degradada (3,5 ha), eucalipto (2 ha) apresentando espaçamento de $3 \times 2 \mathrm{~m}$ 
com dois anos de plantio, bananal (0,6 ha) e pinhão manso (3 ha) com espaçamento de $3 \times 2 m$.

A tabela 1 contém as informações referentes ao regime de chuvas dos meses que antecederam ao levantamento fitossociológico de plantas daninhas (Setembro e Outubro), além do regime no mês em que foi realizado o experimento (dezembro). A precipitação na área de estudo no mês de setembro de 2016 foi caracterizada por baixa incidência de chuvas tendo como maior precipitação $6,70 \mathrm{~mm}$ e um valor médio de $0,59 \mathrm{~mm}$. Já no mês de outubro houve um pequeno aumento na incidência de chuva, tendo como maior precipitação $17,60 \mathrm{~mm}$ e valor médio de 2,15 $\mathrm{mm}$. No mês que as infestantes foram avaliadas em campo a precipitação média foi de 44,20 $\mathrm{mm}$ e este mês teve como valor médio $5,34 \mathrm{~mm}$. A precipitação acumulada nos meses de setembro, outubro e novembro foram respectivamente: 17,6 , 66,7 e 160,1 $\mathrm{mm}$.

TABELA 1: Regime pluviométrico dos meses de setembro, outubro e novembro de 2016

\begin{tabular}{ccccc}
\hline Mês & $\begin{array}{c}\text { Precipitação } \\
\text { média }(\mathbf{m m})\end{array}$ & $\begin{array}{c}\text { Precipitação } \\
\text { máxima }(\mathbf{m m})\end{array}$ & $\begin{array}{c}\text { Precipitação } \\
\text { mínima }(\mathbf{m m})\end{array}$ & $\begin{array}{c}\text { Precipitação } \\
\text { Acumulada }(\mathbf{m m})\end{array}$ \\
\hline Setembro & 0,59 & 6,70 & 0,00 & 17,6 \\
Outubro & 2,15 & 17,60 & 0,00 & 66,7 \\
Novembro & 5,34 & 44,20 & 0,00 & 160,1 \\
\hline
\end{tabular}

As plantas infestantes foram identificadas e quantificadas pelo método do quadrado inventário. Foram utilizados canos de PVC formando um quadrado com medição equivalente a $1 \mathrm{~m}^{2}(1 \mathrm{~m} \times 1 \mathrm{~m})$. Em cada área estudada foram lançadas aleatoriamente 10 parcelas. Em cada quadro amostrado, as plantas foram identificadas, sendo quantificadas as famílias, espécies e nome popular.

Para a análise da população infestante presente, foram calculados e analisados os seguintes parâmetros fitossociológicos (MUELLER-DOMBOIS \& ELLENBERG, 1974): densidade (Den), densidade relativa (Den.R), frequência (Freq), frequência relativa (Freq.R), abundância (Abu), abundância relativa (Abu.R), índice de valor de importância (IVI) e o Índice de valor de importância relativo (IVI.R).

Os parâmetros fitossociológicos foram calculados a partir das seguintes fórmulas:

Den $=\frac{n^{\circ} \text { total de indivíduos por espécie }}{\text { área total de parcelas utilizadas }}$

Den. $R=\frac{\text { densidade da espécie }}{\text { densidade total das espécies }} x 100$

Freq $=\frac{n^{\circ} \text { de parcelas que contém as espécie }}{n^{\circ} \text { total de parcelas utilizadas }}$

Freq. $R=\frac{\text { frequência da espécie }}{\text { frequência total das espécies }} \times 100$

$A b u=\frac{n^{\circ} \text { total de indivíduos por espécie }}{\mathrm{n}^{\circ} \text { total de parcelas com a espécie }}$ 
Abu.R $=\frac{\text { abundância da espécie }}{\text { abundância total das espécies }} \times 100$

$I V I=$ Den $. R+$ Fre. $R+A b u \cdot R$

$I V I . R=\frac{\text { índice de valor de importancia da espécie }}{\text { índice de valor de importancia total das espécies }} \times 100$

A densidade analisa a quantidade de cada indivíduo na área de estudo, sendo expressa em plantas $\mathrm{m}^{-2}$. A frequência quantifica a probabilidade de uma espécie ser encontrada toda vez que o quadrado inventário for lançado aleatoriamente na área de estudo. A abundância verifica quais espécies tem maior ocorrência em agregado, ou seja, as espécies que são encontradas mais próximas umas das outras. E o índice de valor de importância é a junção de todas as estatísticas analisadas, dando uma análise geral de qual espécie tem maior relevância na área amostrada.

\section{RESULTADOS E DISCUSSÃO}

A tabela 2 apresenta as espécies de plantas infestantes que foram encontradas no levantamento fitossociológico das áreas de eucalipto, pastagem degradada, bananal e pinhão-manso na Universidade Federal do Tocantins.

TABELA 2: Relação de plantas daninhas, distribuídas por família, espécie e nome popular, ocorrentes na fazenda experimental da UFT.

\begin{tabular}{|c|c|c|}
\hline Família & Espécie & Nome popular \\
\hline \multirow{2}{*}{ Amaranthaceae } & Alternanthera tenella & Apaga-fogo \\
\hline & Amaranthus deflexus & Caruru rasteiro \\
\hline \multirow{5}{*}{$\begin{array}{c}\text { Asteraceae } \\
\text { Commelinaceae } \\
\text { Convolvulaceae } \\
\text { Cyperaceae } \\
\text { Euphorbiaceae }\end{array}$} & Galinsoga parviflora & Margaridinha \\
\hline & Commelina benghalensis & Trapoeraba \\
\hline & Ipomoea grandifolia & Corda-de-viola \\
\hline & Cyperus esculentus & Tiriricão \\
\hline & Euphorbia heterophylla & Leiteiro \\
\hline \multirow{2}{*}{ Fabaceae } & Mimosa pudica & Malicia \\
\hline & Senna obtusifolia & Mata-pasto \\
\hline Lamiaceae & hyptis lophanta & Catirina \\
\hline \multirow{2}{*}{ Malvaceae } & Sida rhombifolia L. & Malva (guanxuma) \\
\hline & Waltheria Americana & Malva de veludo \\
\hline \multirow[t]{5}{*}{ Phyllanthaceae } & Phyllanthus niruri & Quebra pedra \\
\hline & Brachiaria plantaginea & Capim marmelada \\
\hline & Andropogon gayanus & Capim andropogon \\
\hline & Brachiaria decumbens & Capim braquiária \\
\hline & Cenchrus echinatus & Capim-carrapicho \\
\hline \multirow[t]{5}{*}{ Poaceae } & Cynodon nlemfuensis & Grama estrela africana \\
\hline & Digitaria horizontalis & Capim colchão \\
\hline & Eleusine indica & Capim-pé-de-galinha \\
\hline & Imperata Brasiliensis & Capim agreste \\
\hline & Panicum maximum & Capim colonião \\
\hline Rubiaceae & Diodia teres & Poaia-do-campo \\
\hline
\end{tabular}


Nas áreas estudadas, pôde-se observar maior ocorrência de plantas dicotiledôneas. Foram identificadas 23 espécies distribuídas em 12 famílias (Tabela 2). As famílias que apresentaram maior número de espécies na área de estudo foi a Poaceae, com nove espécies, Fabaceae, com duas espécies, e Amaranthaceae, com duas espécies. Essas três famílias totalizaram $56,5 \%$ das espécies encontradas.

Em estudo avaliando fitossociologia de plantas daninhas em pomar de goiabeiras em diferentes épocas de amostragem LIMA et al. (2015), também encontraram maior porcentagem de espécies pertencentes a família Poacea e Fabaceae. $\mathrm{Na}$ ocasião do estudo os autores dividiram o levantamento em diferentes épocas do ano, outubro, janeiro e junho. As duas famílias somadas totalizaram $38 \%$ das espécies encontradas. Na tabela 3 está descrita a dinâmica da população infestante encontrada no plantio de eucalipto e estatística do levantamento fitossociológico.

TABELA 3: Número de presença em quadrados (NQ), número de indivíduos $(\mathrm{NI})$, frequência (Freq), frequência relativa (Freq.R), densidade (Den), densidade relativa (Den.R), abundância (Abu), abundância relativa (Abu.R), índice de valor de importância (IVI) e índice de valor de importância relativa (IVI.R) das espécies de plantas daninhas avaliadas no plantio de eucalipto na fazenda experimental da Universidade Federal do Tocantins em Gurupi, TO.

\begin{tabular}{|c|c|c|c|c|c|c|c|c|c|c|}
\hline Espécie & NQ & NI & Freq & Freq. $R$ & Den & Den.R & Abu & Abu.R & IVI & IVI.R \\
\hline $\begin{array}{l}\text { Brachiaria } \\
\text { decumbens }\end{array}$ & 7 & 57 & 0,7 & 12,7 & 5,7 & 7,3 & 8,1 & 8,3 & 28,3 & 9,4 \\
\hline Cenchrus echinatus & 1 & 2 & 0,1 & 1,8 & 0,2 & 0,3 & 2,0 & 2,0 & 4,1 & 1,4 \\
\hline Diodia teres & 9 & 252 & 0,9 & 16,4 & 25,2 & 32,5 & 28,0 & 28,4 & 77,3 & 25,8 \\
\hline $\begin{array}{l}\text { hyptis lophanta } \\
\text { Imperata }\end{array}$ & 4 & 49 & 0,4 & 7,3 & 4,9 & 6,3 & 12,3 & 12,4 & 26,0 & 8,7 \\
\hline Brasiliensis & 2 & 3 & 0,2 & 3,6 & 0,3 & 0,4 & 1,5 & 1,5 & 5,5 & 1,8 \\
\hline Mimosa pudica & 10 & 244 & 1 & 18,2 & 24,4 & 31,4 & 24,4 & 24,8 & 74,4 & 24,8 \\
\hline Senna obtusifolia & 7 & 26 & 0,7 & 12,7 & 2,6 & 3,4 & 3,7 & 3,8 & 19,8 & 6,6 \\
\hline $\begin{array}{l}\text { Sida rhombifolia } L \text {. } \\
\text { Waltheria }\end{array}$ & 8 & 107 & 0,8 & 14,5 & 10,7 & 13,8 & 13,4 & 13,6 & 41,9 & 14,0 \\
\hline Americana & 7 & 36 & 0,7 & 12,7 & 3,6 & 4,6 & 5,1 & 5,2 & 22,6 & , \\
\hline
\end{tabular}

$\mathrm{Na}$ área experimental constituída por eucalipto, as espécies mais frequentes encontradas foram: Mimosa pudica, com 1 de frequência e Diodia teres, com 0,9 de frequência. Em relação a distribuição por $\mathrm{m}^{-2}$ as espécies mais encontradas foram: Diodia teres, com 25,2 plantas. $\mathrm{m}^{-2}$ e Mimosa pudica, com 24,4 plantas $\mathrm{m}^{-2}$. As espécies que tiveram maior ocorrência em reboleira foram: Diodia teres, com $28,4 \%$ de abundância e Mimosa pudica, com 24,8\% de abundância. Analisando-se o índice de valor de importância, a espécie com maior destaque na área de eucalipto foi Diodia teres, com IVI de 77,3. E a espécie de menor importância foi a Cenchrus echinatus com IVI de 4,1.

Resultados semelhantes foram encontrados por RIGON et al. (2013), AGRARIAN ACADEMY, Centro Científico Conhecer - Goiânia, v.4, n.7; p.319 2017 
encontraram a espécie Diodia teres em maior frequência e importância em pomar de laranja. A cultura de citros assemelha-se a de eucaliptos no sentido de apresentar elevados espaçamentos, quando comparados com culturas anuais. A alta densidade dessas espécies se dá por não ser palatável aos bovinos, podendo dominar algumas regiões. As espécies de plantas daninhas e a estatística calculada estão na área de pastagem são descritas na tabela 4 ,

TABELA 4: Número de presença em quadrados (NQ), número de indivíduos (NI), frequência (Freq), frequência relativa (Freq.R), densidade (Den), densidade relativa (Den.R), abundância (Abu), abundância relativa (Abu.R), índice de valor de importância (IVI) e índice de valor de importância relativa (IVI.R) das espécies de plantas daninhas avaliadas na área de pastagem na fazenda experimental da Universidade Federal do Tocantins em Gurupi, TO.

\begin{tabular}{lrrrrrrrrrrr}
\hline \multicolumn{1}{c}{ Espécie } & NQ & NI & Freq & Freq.R & Den & Den.R & Abu & Abu.R & IVI & IVI.R \\
\hline $\begin{array}{l}\text { Alternanthera tenella } \\
\text { Brachiaria }\end{array}$ & 1 & 3 & 0,1 & 1,8 & 0,3 & 0,5 & 3,0 & 2,4 & 4,7 & 1,6 \\
decumbens & 2 & 33 & 0,2 & 3,6 & 3,3 & 6,0 & 16,5 & 13,1 & 22,7 & 7,6 \\
$\begin{array}{l}\text { Cenchrus echinatus } \\
\text { Commelina }\end{array}$ & 1 & 15 & 0,1 & 1,8 & 1,5 & 2,7 & 15,0 & 11,9 & 16,5 & 5,5 \\
benghalensis & 9 & 69 & 0,9 & 16,1 & 6,9 & 12,6 & 7,7 & 6,1 & 34,7 & 11,6 \\
Cyperus esculentus & 4 & 70 & 0,4 & 7,1 & 7 & 12,8 & 17,5 & 13,9 & 33,8 & 11,3 \\
Digitaria horizontalis & 3 & 40 & 0,3 & 5,4 & 4 & 7,3 & 13,3 & 10,6 & 23,3 & 7,8 \\
Euphorbia & & & & & & & & & & \\
heterophylla & 8 & 41 & 0,8 & 14,3 & 4,1 & 7,5 & 5,1 & 4,1 & 25,8 & 8,6 \\
Ipomoea grandifolia & 5 & 20 & 0,5 & 8,9 & 2 & 3,6 & 4,0 & 3,2 & 15,8 & 5,3 \\
Mimosa pudica & 3 & 14 & 0,3 & 5,4 & 1,4 & 2,6 & 4,7 & 3,7 & 11,6 & 3,9 \\
Panicum maximum & 8 & 102 & 0,8 & 14,3 & 10,2 & 18,6 & 12,8 & 10,2 & 43,0 & 14,3 \\
Phyllanthus niruri & 5 & 45 & 0,5 & 8,9 & 4,5 & 8,2 & 9,0 & 7,2 & 24,3 & 8,1 \\
Senna obtusifolia & 1 & 1 & 0,1 & 1,8 & 0,1 & 0,2 & 1,0 & 0,8 & 2,8 & 0,9 \\
Sida rhombifolia L. & 6 & 96 & 0,6 & 10,7 & 9,6 & 17,5 & 16,0 & 12,7 & 40,9 & 13,6 \\
\hline
\end{tabular}

$\mathrm{Na}$ área de pastagem degradada teve maior frequência as espécies Commelina benghalensis com 0,9, Euphorbia heterophylla e Panicum maximum, todas com 0,8 de frequência. Em relação a distribuição por $\mathrm{m}^{-2}$ as espécies mais encontradas foram: Panicum maximum, com 10,2 plantas. $\mathrm{m}^{-2}$ e Sida rhombifolia L., com 9,6 plantas $\mathrm{m}^{-2}$. As espécies que tiveram maior ocorrência em reboleira foram: Cyperus esculentus, com $13,9 \%$ de abundância e Sida rhombifolia L., com 12,7\% de abundância. Analisando-se 0 índice de valor de importância, a espécie com maior destaque na área de pastagem degrada foi Panicum maximum, com IVI de 43 . E a espécie de menor importância foi a Senna obtusifolia com IVI de 2,8.

Segundo MANTOANI et al. (2012), a espécie Panicum maximum por ser uma espécie perene e exótica prejudica significativamente a regeneração de espécies nativas dormentes no banco de sementes do solo. Essa espécie coloniza rapidamente solos expostos, tornando-se barreira física para espécies nativas. A estatística do levantamento e as espécies de infestantes encontradas na área de bananal estão descritas na tabela 5 . 
TABELA 5: Número de presença em quadrados (NQ), número de indivíduos (NI), frequência (Freq), frequência relativa (Freq.R), densidade (Den), densidade relativa (Den.R), abundância (Abu), abundância relativa (Abu.R), índice de valor de importância (IVI) e índice de valor de importância relativa (IVI.R) das espécies de plantas daninhas avaliadas na área de bananal na fazenda experimental da Universidade Federal do Tocantins em Gurupi, TO.

\begin{tabular}{lrrrrrrrrrr}
\hline \multicolumn{1}{c}{ Espécie } & NQ & NI & Freq & Freq.R & Den & Den.R & Abu & Abu.R & IVI & IVI.R \\
\hline Alternanthera tenella & 5 & 25 & 0,5 & 11,9 & 2,5 & 5,8 & 5,0 & 5,2 & 22,9 & 7,6 \\
$\begin{array}{l}\text { Amaranthus deflexus } \\
\text { Brachiaria }\end{array}$ & 1 & 1 & 0,1 & 2,4 & 0,1 & 0,2 & 1,0 & 1,0 & 3,7 & 1,2 \\
decumbens & 8 & 145 & 0,8 & 19,0 & 14,5 & 33,7 & 18,1 & 18,9 & 71,7 & 23,9 \\
Commelina & & & & & & & & & & \\
benghalensis & 1 & 6 & 0,1 & 2,4 & 0,6 & 1,4 & 6,0 & 6,3 & 10,0 & 3,3 \\
Cyperus esculentus & 1 & 3 & 0,1 & 2,4 & 0,3 & 0,7 & 3,0 & 3,1 & 6,2 & 2,1 \\
Digitaria horizontalis & 3 & 36 & 0,3 & 7,1 & 3,6 & 8,4 & 12,0 & 12,5 & 28,1 & 9,4 \\
Eleusine indica & 1 & 3 & 0,1 & 2,4 & 0,3 & 0,7 & 3,0 & 3,1 & 6,2 & 2,1 \\
Euphorbia & & & & & & & & & & \\
heterophylla & 2 & 5 & 0,2 & 4,8 & 0,5 & 1,2 & 2,5 & 2,6 & 8,5 & 2,8 \\
Galinsoga parviflora & 1 & 1 & 0,1 & 2,4 & 0,1 & 0,2 & 1,0 & 1,0 & 3,7 & 1,2 \\
Ipomoea grandifolia & 1 & 3 & 0,1 & 2,4 & 0,3 & 0,7 & 3,0 & 3,1 & 6,2 & 2,1 \\
Mimosa pudica & 4 & 110 & 0,4 & 9,5 & 11 & 25,6 & 27,5 & 28,7 & 63,9 & 21,3 \\
Panicum maximum & 1 & 2 & 0,1 & 2,4 & 0,2 & 0,5 & 2,0 & 2,1 & 4,9 & 1,6 \\
Phyllanthus niruri & 4 & 11 & 0,4 & 9,5 & 1,1 & 2,6 & 2,8 & 2,9 & 15,0 & 5,0 \\
Sida rhombifolia L. & 9 & 79 & 0,9 & 21,4 & 7,9 & 18,4 & 8,8 & 9,2 & 49,0 & 16,3 \\
\hline
\end{tabular}

$\mathrm{Na}$ área de bananal as espécies que tiveram maior frequência foram Sida rhombifolia L com 0,9, Brachiaria decumbens com 0,8 e Alternanthera tenella, com 0,5 de frequência. Em relação a distribuição por $\mathrm{m}^{-2}$ as espécies mais encontradas foram: Brachiaria decumbens, com 14,5 plantas $\mathrm{m}^{-2}$ e Mimosa pudica, com 11 plantas $\mathrm{m}^{-2}$. As espécies que tiveram maior ocorrência em reboleira foram: Mimosa pudica, com $28,7 \%$ de abundância e Brachiaria decumbens, com 18,9\% de abundância. Analisando-se o índice de valor de importância, a espécie com maior destaque na área de bananal foi a Mimosa pudica, com IVI de 63,9. E a espécie de menor importância foi a Amaranthus deflexus com IVI de 3,7 (Tabela 5).

Resultados diferentes foram encontrados por LIMA et al. (2012), a distribuição fitossociológica de plantas infestantes na cultura da banana cultivada em Bananeiras - PB teve como espécies de maior destaque a Cyperus rotundus L. Segundo os autores essa espécie tem uma disseminação muito rápida, pois é favorecida pelos tubérculos, que além de serem reserva nutricional para a planta, também são meios de multiplicação da espécie, além de que os autos índices populacionais dessa espécie são favorecidos pela baixa cobertura vegetal. No plantio de pinhão-manso, as espécies e a estatística de cada planta infestante encontrada na área estão descritas na tabela 6 . 
TABELA 6: Número de presença em quadrados (NQ), número de indivíduos (NI), frequência (Freq), frequência relativa (Freq.R), densidade (Den), densidade relativa (Den.R), abundância (Abu), abundância relativa (Abu.R), índice de valor de importância (IVI) e índice de valor de importância relativa (IVI.R) das espécies de plantas daninhas avaliadas no plantio de pinhão manso na fazenda experimental da Universidade Federal do Tocantins em Gurupi, TO.

\begin{tabular}{lrrrrrrrrrrr}
\hline \multicolumn{1}{c}{ Espécie } & NQ & NI & Freq & Freq.R & Den & Den.R & Abu & Abu.R & IVI & IVI.R \\
\hline $\begin{array}{l}\text { Brachiaria } \\
\text { plantaginea }\end{array}$ & 3 & 16 & 0,3 & 5,2 & 1,6 & 1,9 & 5,3 & 4,5 & 11,6 & 3,9 \\
$\begin{array}{l}\text { Euphorbia } \\
\text { heterophylla }\end{array}$ & 2 & 2 & 0,2 & 3,4 & 0,2 & 0,2 & 1,0 & 0,8 & 4,5 & 1,5 \\
$\begin{array}{l}\text { Andropogon gayanus } \\
\text { Brachiaria }\end{array}$ & 4 & 30 & 0,4 & 6,9 & 3 & 3,5 & 7,5 & 6,3 & 16,8 & 5,6 \\
decumbens & 7 & 43 & 0,7 & 12,1 & 4,3 & 5,1 & 6,1 & 5,2 & 22,3 & 7,4 \\
$\begin{array}{l}\text { Cynodon } \\
\text { nlemfuensis }\end{array}$ & 3 & 19 & 0,3 & 5,2 & 1,9 & 2,2 & 6,3 & 5,3 & 12,8 & 4,3 \\
Digitaria horizontalis & 8 & 637 & 0,8 & 13,8 & 64 & 75,3 & 79,6 & 67,1 & 156,2 & 52,1 \\
Mimosa pudica & 10 & 32 & 1 & 17,2 & 3,2 & 3,8 & 3,2 & 2,7 & 23,7 & 7,9 \\
Senna obtusifolia & 7 & 11 & 0,7 & 12,1 & 1,1 & 1,3 & 1,6 & 1,3 & 14,7 & 4,9 \\
Sida rhombifolia L. & 7 & 39 & 0,7 & 12,1 & 3,9 & 4,6 & 5,6 & 4,7 & 21,4 & 7,1 \\
Waltheria Americana & 7 & 17 & 0,7 & 12,1 & 1,7 & 2,0 & 2,4 & 2,0 & 16,1 & 5,4 \\
\hline
\end{tabular}

$\mathrm{Na}$ área de pinhão-manso teve maior frequência as espécies Digitaria horizontalis com 0,8, Brachiaria decumbens, Senna obtusifolia, Sida rhombifolia L. e Waltheria Americana, todas com 0,7 de frequência. Em relação a distribuição por $\mathrm{m}^{-2}$ as espécies mais encontradas foram: Digitaria horizontalis, com 64 plantas $\mathrm{m}^{-2} \mathrm{e}$ Brachiaria decumbens, com 4,3 plantas $\mathrm{m}^{-2}$. As espécies que tiveram maior ocorrência em reboleira foram: Digitaria horizontalis, com $67,1 \%$ de abundância e Andropogon gayanus, com 6,3\% de abundância. Analisando-se o índice de valor de importância, a espécie com maior destaque na área de pinhão-manso foi a Digitaria horizontalis, com IVI de 156,2. E a espécie de menor importância foi a Euphorbia heterophylla com IVI de 4,5 (Tabela 6).

TAVARES et al. (2013), encontraram resultados semelhantes em levantamento fitossociológico na cultura do feijão. Estes autores realizaram diversos levantamentos no decorrer do ano, sendo que no mês de outubro a espécie que obteve maior importância em relação as demais foi a Digitaria horizontalis. Fato que corrobora com os resultados do presente estudo, realizado no mês de dezembro. LIMA et al. (2014), constataram que a espécie Digitaria horizontalis é adaptada a região central do Brasil, e que essa espécie se desenvolve nos estágios iniciais do desenvolvimento de culturas.

\section{CONCLUSÕES}

- A partir do levantamento fitossociológico pode-se obter valiosas informações sobre a composição florística das plantas infestantes das diferentes áreas analisadas.

- As espécies que se apresentaram mais frequentes nas áreas foram: Diodia teres, Commeliana benghalensis e Sida rhombifolia.

- As espécies que foram encontradas em maior densidade foram: Diodia AGRARIAN ACADEMY, Centro Científico Conhecer - Goiânia, v.4, n.7; p.322 2017 
teres, Panicum maximum e Brachiaria decumbens.

- Em reboleira, as espécies que apresentaram essa característica foram: Mimosa pudica, Diodia teres e Cyperus esculentus.

- No geral, as espécies mais importantes foram: Diodia teres, Panicum maximum, Mimosa pudica e Digitaria horizontales.

\section{REFERÊNCIAS}

LIMA, K. S.; ARAÚJO, R. C.; SANTOS, J. P. S.; LOPES, M. F. Q. Fitossociologia de plantas daninhas em pomar de goiabeiras em diferentes épocas de amostragem. Revista Biociências, v. 21, n. 1, p. 45-55, 2015. Disponível em: <http://periodicos.unitau.br/ojs-2.2/index.php/biociencias/article/viewFile/2001/1513>

LIMA, L. K. S.; BARBOSA, A. J. S.; SILVA, R. T. L.; ARAÚJO, R. C. Distribuição fitossociológica da comunidade de plantas espontâneas na bananicultura. Revista Verde de Agroecologia e Desenvolvimento Sustentável, v. 7 , n. 4, p. 59-68, 2012.

LIMA, S. F.; TIMOSSI, P. C.; ALMEIDA, D. P.; SILVA, U. R. Fitossociologia de plantas daninhas em convivência com plantas de cobertura. Revista Caatinga, v. 27, n. 2, p. 37-47, 2014. Disponível em: < http://www.redalyc.org/pdf/2371/237131344005.pdf >

MANTOANI, M. C.; ANDRADE, G. R.; CAVALHEIRO, A. L.; TOREZAN, J. M. D. Efeitos da invasão por Panicum maximum Jacq. e do seu controle manual sobre a regeneração de plantas lenhosas no sub-bosque de um reflorestamento. Semina: Ciências Biológicas e da Saúde, v. 33, n. 1, p. 97-110, 2012. DOI: 10.5433/16790367.2012v33n1p97

MATA, J. F.; BIANCO, S.; MACHADO, R. D.; FERREIRA, J. H. S. Fitossociologia de plantas daninhas na cana-de-açúcar sob desenvolvimento em área de cana crua. In: XXI Congreso Latinoamericano de Malezas e XXXIV Congreso de la ASOMECIMA., 2013, Cancun. Memoria del XXI Congreso Latinoamericano de Malezas y XXXIV Congreso de la ASOMECIMA, 2013. p. 1-6.

MOURA FILHO, E. R.; MACEDO, L. P. M.; SILVA, A. R. S. Levantamento fitossociológico de plantas daninhas em cultivo de banana irrigada. Holos (Natal. Online), v. 2, p. 92-97, 2015. DOI: 10.15628/holos.2015.1006

MUELLER-DOMBOIS, D. e ELLENBERG, H. Aims and methods of vegetation ecology. New York: John Wiley e Sons, p. 547. 1974.

PACHECO, L. P.; PETTER, F.A.; SOARES, L. S.; SILVA, R. F.; OLIVEIRA, J. B. S. Sistemas de produção no controle de plantas espontâneas em culturas anuais no Cerrado Piauiense. Revista Ciência Agronômica (UFC. Impresso), v. 47, n.3, p. 500-508, 2016. Disponível em: < http://ccarevista.ufc.br/seer/index.php/ccarevista/article/view/4029>

RIGON, C. A. G.; RIGON, J. P. G.; CAPUANI, S.; ABRAWICZ, J. Levantamento florístico de plantas daninhas em pomar de laranja na região das missões do Rio 
Grande do Sul. Anais do SEPE-Seminário de Ensino, Pesquisa e Extensão da UFFS, $\quad$ v. $2, \quad$ n. $\quad 1, \quad 2013 . \quad$ Disponível em: $<$ https://periodicos.uffs.edu.br/index.php/SEPE-UFFS/article/view/357/70 >

RODRIGUES, A. P. M. S.; MENDONÇA JUNIOR, A. F.; COSTA, E. M.; ARAÚJO, J. A. M.; DE PAULA, V. F. S. Levantamento fitossociológico de plantas daninhas na cultura da cenoura em monocultivo e consorciada com rabanete. Revista Verde de Agroecologia e Desenvolvimento Sustentável, v. 11, n. 1, p. 73-77, 2016. DOI: $10.18378 /$ rvads.v11i1.4450

SEPLAN - Secretaria do Planejamento e da Modernização da Gestão Pública . Superintendência de Pesquisa e Zoneamento Ecológico Econômico. Diretoria de Zoneamento Ecológico-Econômico. Atlas do Tocantins: subsídios ao Planejamento da Gestão Territorial. 6. ed. rev. atua. BORGES, R. S. T.; DIAS, R. R.; SOUSA, P. A. B. (orgs.) Palmas: Seplan, 2012. 80 p.

TAVARES, C. J.; JAKELAITIS, A.; REZENDE, B. P. M.; CUNHA, P. C. R. Fitossociologia de plantas daninhas na cultura do feijão. Agrária - Revista Brasileira de Ciências Agrárias, v. 8, n. 1, p. 27-32, 2013. DOI: 10.5039/agraria.v8i1a1849 